\title{
BEHAVIOR OF RIVER OTTERS IN THE OXBOW BEND VICINITY, Grand Teton National Park
}

\author{
JOSEPH G. HALL $\downarrow$ DEPARTMENT OF BIOLOGY \\ SAN FRANCISCO STATE UNIVERSITY $\downarrow \mathrm{CA}$
}

\section{$\downarrow \quad$ OBJECTIVES AND METHODS}

The 1996 project was a continuation of the study begun in 1995 - to obtain information on movements, sociability, and activity patterns of river otters in the Oxbow region of the Snake River within Grand Teton National Park. Particular emphasis was on nocturnal patterns as documented by automatic cameras activated by buried treadleswitches in places otters were known to frequent, such as latrines, resting sites and feeding sites. Daytime activity was monitored both by the cameras and by routine canoe patrols. Field work was carried out July 5 - August 5.

\section{$\downarrow \quad$ RESULTS}

A strong social bond was observed in otters. Of 16 encounters (both direct and indirect) only one lone otter was noted. The remainder consisted of from two to six animals, the average size being 3.6 individuals. The typical group was one adult and one or more juveniles.

For reasons unknown to me, the 1996 summer season was considerably less productive than the previous year. The camera equipment was substantially improved in 1996 and hours of monitoring were increased from 1,200 to 1,700 . Yet only three otter visits were recorded at two sites. Perhaps part of the problem could be accounted for by increased "vandalism" by other animals. On three occasions cameras were disabled by being knocked over, presumably by curious moose. On another occasion a camera was disabled, apparently by a coyote which knocked the camera over and gnawed into a battery compartment. The final disabled camera resulted from an otter digging up the buried treadle switch. Fortunately, no evidence of human interference was noted. Due to a combination of reasons, the "cost" per photograph rose from 120 monitor-hours in 1995 to 566 in 1996, almost a five-fold ratio!

As expected, animals other than otters occasionally triggered the cameras. A coyote stepped on the treadle one night and a long-tailed weasel did the same on another night. No nighttime visits were recorded for otters. All three otter visits occurred by day: 0833, 1345, and 1945. (Figure 1) Although the sample size remains quite small, the cumulative records for 1995 and 1996 suggest that otter activity is about evenly divided between day and night. A larger sample size should yield a ratio in which one would have more confidence. 


\section{$\downarrow \quad$ ACKNOWLEDGMENTS}

It is a pleasure to thank those who volunteered to assist me again in the field, some for the second consecutive season. They helped not only in loading and unloading the canoe but in setting up and maintaining monitors and as keen- eyed observers of otters on our canoe patrols. They are Kathleen McGinley, Bob Richardson, Peter Mui (who also improved the monitor circuits), Eric Ruby, Tony Link, Kevin and Brenda Sabo, Melissa Brown, my wife, Betty, and daughters Sally and Peggy.

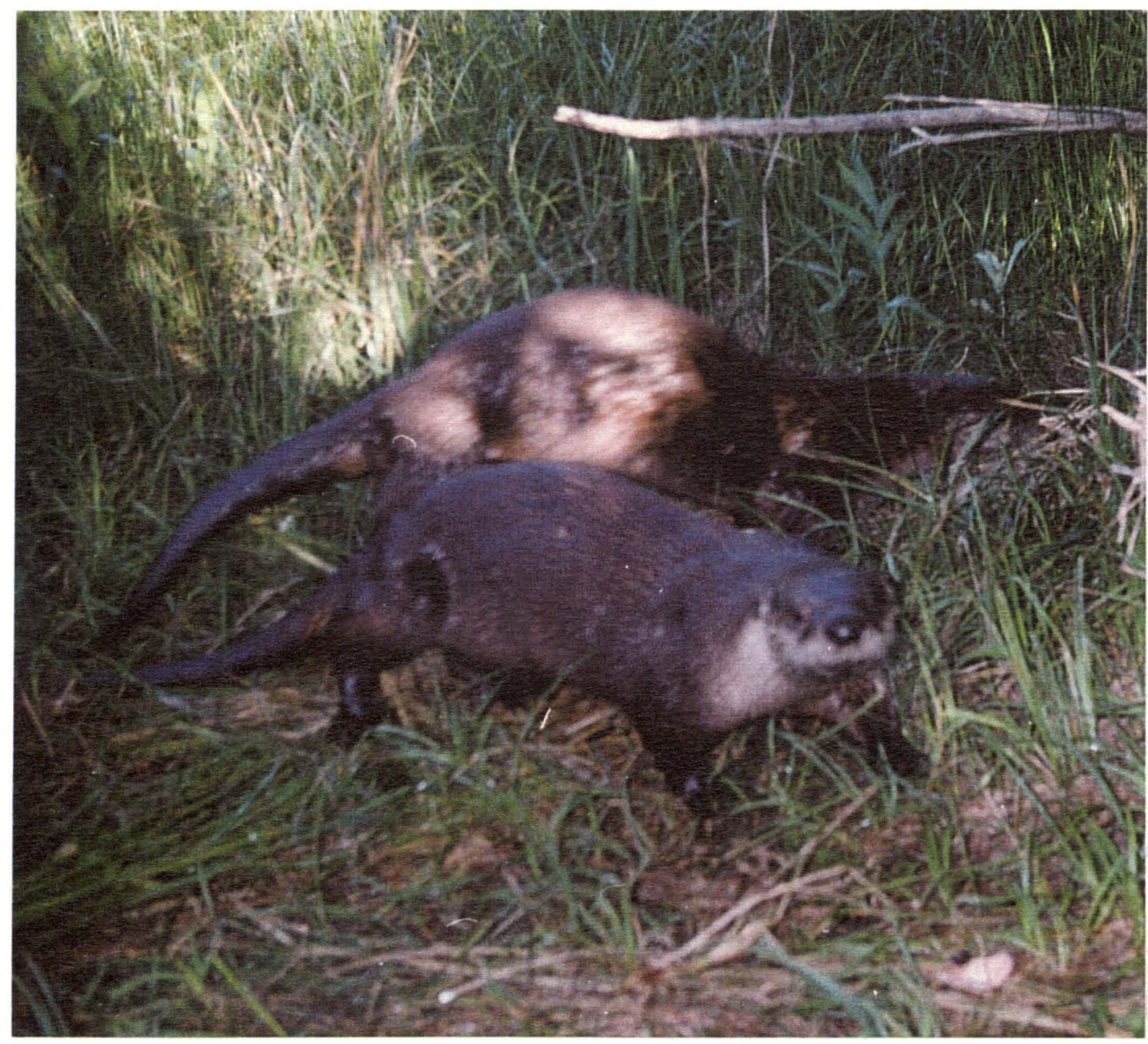

Figure 1. Adult and juvenile above Cattlemen's Bridge 1300, August 1 